\title{
Educational Research, for Better or Verse
}

\author{
Joel R. Levin
}

Published online: 7 May 2011

(C) Springer Science+Business Media, LLC 2011

Keywords Educational research $\cdot$ Methodology

(Originally composed in April 2003)

Cahnmann's (2003) thesis that educational research can benefit from a healthy dose of poetry deserves a response in kind. What follows is a modest offering.

\section{Owed to Cahnmann (2003)}

I thought that I would never see

Educational research reduced to poe-tree.

Through metaphor, artistic device

Come, tackle research issues slice by slice!

Probing deeply, metaphorically speaking

We'll give our powerful poetic tools a tweaking.

As we seek to understand effects and causes

Through fundamentally sound words and clauses.

Leaving no unexplained phenomenon unturned

We'll apply all the methodological tricks we've learned.

Till stanza by stanza, measure by measure

We've unearthed every worldly research treasure.

Other research approaches? To hell with 'em!

For after all, we've got rhyme and rhythm.

And while performing our craft on the shoulders of giants

We can even spread the word to medical science.

Imagine Secretary Whitehurst's elation

At our bold new educational research innovation!

So thanks be to you, our AERA,

For bringing us "Educational Research as ABBA."

\section{Reference}

Cahnmann, M. (2003). The craft, practice, and possibility of poetry in educational research. Educational Researcher, 32(3), 29-36.

J. R. Levin (ه)

University of Arizona, 3850 E. Placita de Peri, Tucson, AZ 85718, USA

e-mail: jrlevin@u.arizona.edu 